\title{
Gamma Knife surgery for patients with brainstem metastases
}

\author{
Clinical article
}

\author{
Takuya Kawabe, M.D., ${ }^{1,2}$ Masaaki Yamamoto, M.D., ${ }^{1,3}$ Yasunori Sato, Ph.D., ${ }^{4}$ \\ Bierta E. Barfod, M.D., ${ }^{1}$ Yoichi Urakawa, M.D., ${ }^{1}$ Hidetoshi Kasuya, M.D., ${ }^{3}$ \\ and Katsuyoshi Mineura, M.D. ${ }^{2}$
}

\begin{abstract}
${ }^{1}$ Katsuta Hospital Mito GammaHouse, Hitachi-naka; ${ }^{2}$ Department of Neurosurgery, Kyoto Prefectural University of Medicine, Graduate School of Medical Science, Kyoto; ${ }^{3}$ Department of Neurosurgery, Tokyo Women's Medical University Medical Center East, Tokyo; and ${ }^{4}$ Clinical Research Center, Chiba University Graduate School of Medicine, Chiba, Japan
\end{abstract}

\begin{abstract}
Object. Because brainstem metastases are not deemed resectable, stereotactic radiosurgery (SRS) is the only treatment modality expected to achieve a radical cure. The authors describe their treatment results, focusing particularly on how long patients can survive without neurological deterioration following SRS for brainstem metastases.

Methods. This was an institutional review board-approved, retrospective cohort study in which the authors pulled from their database information on 2553 consecutive patients with brain metastases who underwent Gamma Knife surgery (GKS) at the Mito GammaHouse between July 1998 and July 2011. Among the 2553 patients, excluding cases in which there was meningeal dissemination, 200 cases of brainstem metastases (78 women and 122 men with a mean age of 64 years [range 36-86 years]) were identified and analyzed. The most common primary site was the lung (137 patients) followed by the gastrointestinal tract ( 24 patients), breast (17 patients), kidney (12 patients), and others (10 patients). Among the 200 patients, 15 patients (7.5\%) harbored at least 2 tumors in the brainstem: 11 patients had 2 tumors, 2 patients had 3 tumors, and 1 patient each had 4 or 5 tumors. Therefore, a total of 222 tumors were irradiated. These 222 tumors were located in the pons (121 lesions), the midbrain (65 lesions), and the medulla oblongata (36 lesions). The mean and median tumor volumes were 1.3 and $0.2 \mathrm{~cm}^{3}$ (range $0.005-10.7 \mathrm{~cm}^{3}$ ), and the median peripheral radiation dose was $18.0 \mathrm{~Gy}$ (range 12.0-25.0 Gy).

Results. The overall median survival time (MST) was 6.0 months. Distribution of MSTs across Recursive Partitioning Analysis (RPA) classes showed that the MSTs were 9.4 months in Class I (20 patients), 6.0 months in Class II (171 patients), and 1.9 months in Class III (9 patients). Better Karnofsky Performance Scale score, single metastasis, and well-controlled primary tumor were significant predictive factors for longer survival. The neurological and qualitative survival rates were $90.8 \%$ and $89.2 \%$, respectively, at 24 months post-GKS. Better KPS score and smaller tumor volume tended to be associated with prolonged qualitative survival. Follow-up imaging studies were available for 129 patients $(64.5 \%)$. The tumor control rate was $81.8 \%$ at 24 months post-GKS. Smaller tumor volume tended to contribute to tumor control.

Conclusions. The present results indicate that GKS is effective in the treatment of brainstem metastases, particularly from the viewpoint of maintaining a good neurological condition in the patient. (http://thejns.org/doi/abs/10.3171/2012.7.GKS12977)
\end{abstract}

\section{Key Words - Gamma Knife surgery - stereotactic radiosurgery • brainstem - metastasis}

$\mathrm{B}$ RAIN metastases are a common, life-threatening neurological problem in the absence of effective treatment for patients with cancer. In particular, metastatic lesions located in the brainstem, although uncommon (1.5\%-11\% of all brain metastases), are clinically the most crucial lesions because of the brainstem's anatomical location and critical functions.$^{4,8-10,13}$ Historically, WBRT has played the dominant role in manage-

Abbreviations used in this paper: BSBM = Basic Score for Brain Metastases; GKS = Gamma Knife surgery; GPA = Graded Prognostic Assessment; HR = hazard ratio; KPS = Karnofsky Performance Scale; LINAC = linear accelerator; MET-PET = L-[methyl- $\left.{ }^{11} \mathrm{C}\right]$ methionine positron emission tomography; MST $=$ mean survival time; RPA = recursive partitioning analysis; SIR = Score Index for Radiosurgery; SRS = stereotactic radiosurgery; $\mathrm{WBRT}=$ whole brain radiation treatment. ment recommendations, because brainstem metastases have not been deemed resectable, even when the most recent advances in microsurgical techniques have been used. Recently, SRS plus WBRT has been recommended as the first treatment for patients with brain metastases. ${ }^{1}$ However, a debate persists as to whether WBRT is necessary for all patients with brain metastasis. The primary argument against WBRT stems from the risk of deterioration of neurocognitive function, which cannot be ignored in long-surviving patients. . $^{2,319}$

More than 10 authors recently reported the clinical efficacy of using SRS alone to treat brainstem metastases; their findings were based on relatively small patient populations - 22 to 60 patients per study. ${ }^{4,7,8,10,13-16,18,22,25,28,33,34}$ Although patients' overall survival, factors impacting survival, and/or local tumor control rates were described 
in these reports, functional survival has not yet been analyzed. Approximately $90 \%$ of patients died of extracerebral diseases in a subset in which SRS was performed..$^{30,31}$ Thus, treatments for brain metastasis are crucial for maintaining the patient's good neurological state as long as possible. In this report, based on a relatively large patient population, we describe our treatment results, focusing particularly on this issue.

\section{Patient Population}

\section{Methods}

This study was approved by the Tokyo Women's Medical University's institutional review board. It is a retrospective cohort study in which we used a prospectively accumulated database that includes 2553 consecutive patients with brain metastases who underwent GKS alone, without WBRT, at the Katsuta Hospital Mito GammaHouse during the 13-year period, July 1998-July 2011. The treatment strategy was explained in detail to each patient and at least one adult relative by one of the authors (M.Y.) before GKS was performed. Written informed consent was obtained from all cases. From our database of 2553 patients with brain metastases, $200(7.8 \%)$ with brainstem metastases were identified and included in our study population. Patients in whom there was meningeal dissemination and patients undergoing three-stage GKS were excluded from the study.

Table 1 summarizes the clinical characteristics in our patient population. There were 78 women (39\%) and 122 men $(61 \%)$. The mean age of the patients at the time of radiosurgery was 64 years (range $36-86$ years). The most common primary site was the lung (137 patients; $68.5 \%$ ) followed by the gastrointestinal tract (24 patients; $12 \%)$, breast (17 patients; 8.5\%), kidney (12 patients; 6\%), and other locations (10 patients; 5\%, including 1 melanoma). Among the 200 patients, $15(7.5 \%)$ had $\geq 2$ tumors in the brainstem: 11 patients harbored 2 tumors; 2 patients harbored 3,1 patient harbored 4 , and 1 patient harbored 5 . Thus, 222 tumors in all were irradiated. Among the 222 tumors, the location distribution was the pons for 121 lesions (54.5\%), the midbrain for 65 lesions (29.3\%), and the medulla oblongata for 36 lesions (16.2\%). The brainstem was the only tumor location in 24 patients (12\%), whereas the other 176 patients (88\%) also harbored nonbrainstem tumors.

The median radiation dose directed at the tumor periphery was 18.0 Gy (range 12.0-25.0 Gy), and the median dose directed at the tumor center (maximum dose) was 30.0 Gy (range 20.0-40.0 Gy).

The primary cancer was reported by the referring primary physician to be well controlled in 61 patients (30.5\%). A total of 88 patients (44\%) had nonbrain metastases as well. The median KPS score ${ }^{12}$ at the time of radiosurgery was $90 \%$ (range $50 \%-100 \%$ ). The KPS was $80 \%$ or better in 156 patients (78\%) and 70\% or worse in 44 patients (22\%). According to the Radiation Therapy Oncology Group's RPA classification system,, 20 patients (10\%) were in RPA Class I, 171 patients $(85.5 \%)$ in RPA Class II, and 9 patients $(4.5 \%)$ in RPA Class III. Fifty patients had various symptoms caused by brainstem lesions, such as hemiparesis (27 patients), diplopia (10 patients), head-
TABLE 1: Summary of clinical characteristics in 200 patients with 222 brainstem metastases

\begin{tabular}{|c|c|}
\hline Characteristic & Value \\
\hline \multicolumn{2}{|l|}{ sex-no. of patients (\%) } \\
\hline women & $78(39)$ \\
\hline men & $122(61)$ \\
\hline mean age in yrs (range) & $64(36-86)$ \\
\hline \multicolumn{2}{|c|}{ location of primary cancer-no. of lesions (\%) } \\
\hline lung & $137(68.5)$ \\
\hline gastrointestinal tract & $24(12)$ \\
\hline breast & $17(8.5)$ \\
\hline kidney & $12(6)$ \\
\hline other & $10(5)$ \\
\hline \multicolumn{2}{|l|}{ mean/median no. of tumors (range) } \\
\hline whole brain & $7 / 6(1-19)$ \\
\hline brainstem & $1 / 1(1-5)$ \\
\hline \multicolumn{2}{|c|}{ location in brainstem location-no. of lesions (\%) } \\
\hline pons & $121(54.5)$ \\
\hline midbrain & $65(29.3)$ \\
\hline medulla oblongata & $36(16.2)$ \\
\hline \multicolumn{2}{|c|}{ control of primary cancer-no. of patients (\%) } \\
\hline controlled & $61(30.5)$ \\
\hline not controlled & $139(69.5)$ \\
\hline \multicolumn{2}{|c|}{ extracerebral metastases—no. of patients (\%) } \\
\hline no & $112(56)$ \\
\hline yes & $88(44)$ \\
\hline \multicolumn{2}{|l|}{ KPS score-no. of patients (\%) } \\
\hline$\geq 80 \%$ & $156(78)$ \\
\hline$\leq 70 \%$ & $44(22)$ \\
\hline \multicolumn{2}{|l|}{ RPA class-no. of patients (\%) } \\
\hline I & $20(10)$ \\
\hline II & $171(85.5)$ \\
\hline III & $9(4.5)$ \\
\hline \multicolumn{2}{|l|}{ brainstem symptom(s) -no. of patients (\%) } \\
\hline no & $150(75)$ \\
\hline yes & $50(25)$ \\
\hline \multicolumn{2}{|l|}{ prior surgery-no. of patients (\%) } \\
\hline no & $198(99)$ \\
\hline yes & $2(1)$ \\
\hline \multicolumn{2}{|l|}{ prior WBRT-no. of patients (\%) } \\
\hline no & $187(93.5)$ \\
\hline yes & $13(6.5)$ \\
\hline median tumor volume in $\mathrm{cm}^{3}$ (range) & $0.2(0.005-10.7)$ \\
\hline median peripheral dose in Gy (range) & $18.0(12.0-25.0)$ \\
\hline
\end{tabular}

ache and consciousness disturbance caused by obstructive hydrocephalus (7 patients), dysphagia (6 patients), and so on. Prior treatments performed at other facilities included surgical removal (including biopsy) of brainstem lesions in 2 patients and WBRT (30 Gy/10 fractions) in 13 patients.

\section{Statistical Analysis}

Neurological and neuroimaging evaluations were 
performed every 2-3 months after the initial GKS. Overall survival time was defined as the interval between the first SRS for brainstem metastasis and death due to any cause or the day of the last follow-up. Neurological death was defined as death caused by all intracranial diseases: tumor recurrence, carcinomatous meningitis, cerebral dissemination, and progression of other untreated intracranial tumors. Neurological death-free survival time was defined as the interval between the first SRS for brainstem metastasis and the day of any brain diseasecaused death or the day of the last follow-up.

Control of the GKS-treated lesion was defined as no remarkable increase, namely regression or unchanged, in tumor diameter. Generally, the local recurrence criteria were increased size $(>10 \%$ increase in maximum diameter) of an enhanced area on gadolinium-enhanced T1-weighted MR images and an enlarged tumor core on T2-weighted MR images. ${ }^{11}$ However, in some cases, in which MR imaging alone was not sufficient to confirm recurrence, MET-PET was very useful for distinguishing tumor recurrence from necrotic lesions. ${ }^{20,27}$ Qualitative survival time was defined as the interval between the first GKS and the day that the KPS score decreased to below $70 \%$ (functionally dependent) due to neurological status.

All data were analyzed according to the intention-totreat principle. For baseline variables, summary statistics were constructed that used frequencies and proportions for categorical data and means and standard deviations for continuous variables. We compared patient characteristics using the Fisher exact test for categorical outcomes and t-tests for continuous variables, as appropriate. For time-to-event outcomes, times elapsed until a first event were compared using the log-rank test. The Kaplan-Meier method $^{11}$ was used to estimate the absolute risk of each event for each group, and hazard ratios and 95\% confidence intervals were estimated with the aid of the Cox proportional hazards model. In addition, the cumulative incidences of neurological death, impaired neurological status, and local tumor control failure were estimated by performing a competing risk analysis, because death is a competing risk for lost to follow-up. ${ }^{6,23}$

All comparisons were planned, and the tests were two-sided. A p value less than 0.05 was determined to indicate a statistically significant difference. All statistical analyses were conducted using JMP (version 8.0.2, SAS Institute Inc.). Competing risk analyses were performed by one of the authors (Y.S.), who was not involved in either the GKS treatment or patient follow-up, by using SAS software (version 9.2, SAS Institute Inc.).

\section{Results}

\section{Overall Survival}

The median post-GKS follow-up time among censored observations (21 patients) was 5.8 months (range $0.2-120.2)$, and 179 patients (89.5\%) had died as of the end of August 2011. The MST was 6.0 months (95\% CI 5.2-7.3) after GKS was performed to treat brainstem metastases. The Kaplan-Meier plots of all 200 patients are shown in Fig. 1 upper. Kaplan-Meier estimated survival rates were $50.6 \%, 31.0 \%$, and $8.7 \%$ at 6,12 , and 24 months post-GKS, respectively. The MSTs according to the primary cancer sites were 6.0 months (95\% CI 4.9-8.0), 5.1 months (95\% CI 2.2-7.4), 6.0 months (95\% CI 1.8-16.6), and 11.2 months (95\% CI 2.6-19.0) in patients with lung, gastrointestinal tract, breast, and renal tumors, respectively. There were no statistically significant differences in survival times among the original cancers $(p=0.427)$. According to the RPA classification, the MSTs were 9.4 months (95\% CI 5.5-16.6) for Class I, 6.0 months (95\% CI 4.9-7.1) for Class II, and 1.9 months (95\% CI 0.3-6.9) for Class III (Fig. 1 lower). Although there was a statistically significant difference with the three-group stratification $(\mathrm{p}<0.001)$, Classes I and II did not differ significantly $(\mathrm{p}=0.175)$.

Factors Predicting Longer Survival Period

As shown in Table 2, among the 10 clinical factors an-

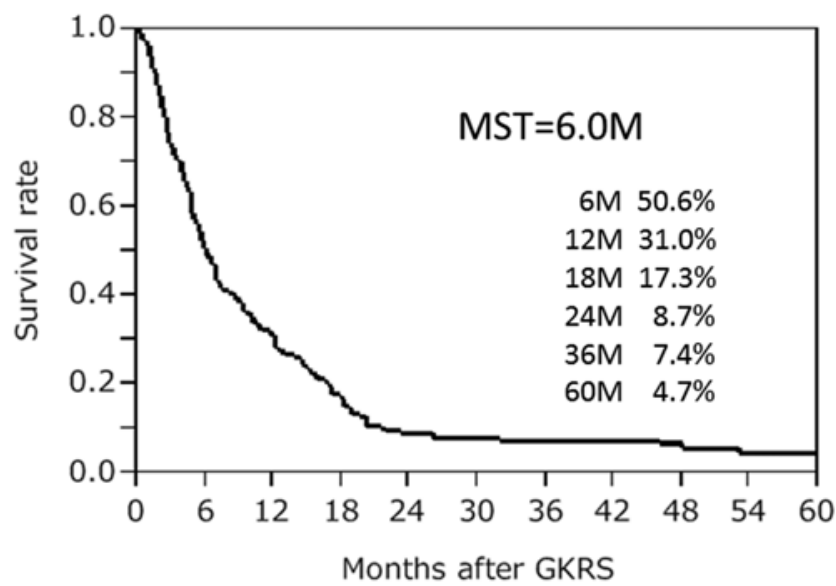

Number at risk $\begin{array}{lllllllllll}200 & 98 & 58 & 30 & 13 & 12 & 11 & 10 & 7 & 6 & 5\end{array}$

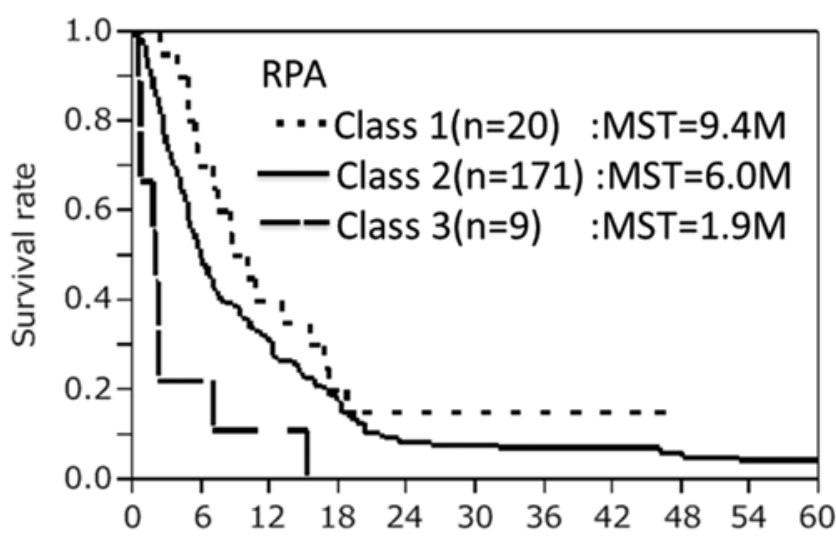

Months after GKRS

Number at risk
1) $20 \quad 14 \quad 8$

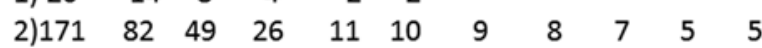
3) 9210

Fig. 1. Overall survival (upper) and survival stratified by RPA classes (lower), estimated using the standard Kaplan-Meier method. $M=$ months. Numbers of patients at risk for each time point are indicated below each graph. 
alyzed (patient age and sex, KPS score, number of tumors, tumor volume, peripheral dose, primary tumor status, nonbrain metastasis, neurological brainstem symptoms, and prior WBRT), univariate analyses showed that 4 of them significantly favored longer survival: 1) better KPS score ( $\mathrm{p}<0.001 ; \mathrm{HR}=4.966$ [95\% CI 2.666-9.134]); 2) single metastasis $(\mathrm{p}=0.005$; $\mathrm{HR}=2.097$ [95\% CI 1.2513.473]); 3) smaller tumor volume ( $\mathrm{p}=0.041 ; \mathrm{HR}=2.199$ [95\% CI 1.035-4.288]); and 4) well-controlled primary tumor $(\mathrm{p}<0.001$; HR $=1.762$ [95\% CI 1.278-2.465]). The multivariate analyses showed 3 clinical factors that significantly favored longer survival: 1) better KPS score ( $\mathrm{p}<0.001 ; \mathrm{HR}=5.416$ [95\% CI 2.507-11.479]); 2) single metastasis $(\mathrm{p}=0.012 ; \mathrm{HR}=2.065$ [95\% CI 1.174-3.598]); and 3) well-controlled primary tumors $(\mathrm{p}=0.021$; $\mathrm{HR}=$ 1.494 [95\% CI 1.061-2.128]).

\section{Neurological Survival}

Among the 180 deceased patients, the cause of death could not be determined in 5 but was confirmed in the remaining 175 patients: nonbrain disease in 156 patients (89.1\%), progression of brain metastases in 15 patients (8.6\%), and both in 4 patients (2.3\%). In the 156 patients who died of their primary cancer or nonbrain metastases, good brain condition was maintained until 1 to several days before death. In the 19 patients who died of progression of brain metastases, only 4 died of progression of brainstem metastases. The neurological survival rate was $90.8 \%$ at 24 months post-GKS (Fig. 2A). Among the aforementioned 10 clinical factors, none were statistically significant, but the univariate analyses revealed that 1 of them, smaller tumor volume, tended to be associated with longer neurological survival $(\mathrm{p}=0.057)$.

\section{Qualitative Survival}

We did not perform GKS in patients with low KPS scores due to systemic disease. Thus, only 9 patients with low KPS scores were treated with GKS for brainstem metastases: 1 patient with a KPS score of $50 \%$ and 8 patients with a KPS score of $60 \%$. After treatment, a deterioration in performance occurred in 27 cases. The qualitative survival rate was $90.8 \%$ at 24 months post-GKS (Fig. 2B). Among the 10 clinical factors, the univariate analyses showed 2 factors that significantly favored longer survival: 1) better KPS score ( $\mathrm{p}=0.009$; HR $=8.394$ [95\% CI 1.717-39.654]); and 2) smaller tumor volume ( $\mathrm{p}=0.026$; $\mathrm{HR}=6.284$ [95\% CI 1.286-22.621]). However, according to the multivariate analyses, neither factor was statistically significant (better KPS score, $\mathrm{p}=0.172$; smaller tumor volume, $\mathrm{p}=0.222$ ).

\section{Follow-Up MR Imaging and Local Tumor Control}

In this series, follow-up MR images were available for 129 patients $(65 \%)$. Local recurrence of treated brainstem lesions occurred in 22 patients $(17.1 \%)$. KaplanMeier-estimated local control rates were $93.6 \%, 82.7 \%$, and $81.8 \%$ at 6,12 , and 24 months post-GKS, respectively (Fig. 2C). Among the 22 patients in whom there was local control failure, 13 underwent repeated GKS. Among these 13 patients, MET-PET was used for GKS dose planning in 5 patients. At the second GKS, the median dose at the tumor periphery was 15.0 Gy (range 9.0-17.5 Gy). In the 8 patients $(62 \%)$ in whom post-GKS follow-up MR images were available, the images demonstrated treated tumors to be well controlled in 5 patients and not well controlled in the other 3.

Among the 10 clinical factors, the univariate analyses showed that smaller tumor volume, as a continuous variable, tended to impact the local control rate, although the association did not reach the level of statistical significance $(p=0.202)$. However, if tumor volume was analyzed as a categorical variable, that is, $<1.0 \mathrm{~cm}^{3}$ versus $\geq 1.0 \mathrm{~cm}^{3}$ or $<3.0 \mathrm{~cm}^{3}$ versus $\geq 3.0 \mathrm{~cm}^{3}$, as reported, 7,14 incidences of local recurrence were significantly lower in patients with smaller tumors than in patients with larger tumors: $<1.0 \mathrm{~cm}^{3}$ versus $\geq 1.0 \mathrm{~cm}^{3}(\mathrm{p}=0.020)$ compared with $<3.0 \mathrm{~cm}^{3}$ versus $\geq 3.0 \mathrm{~cm}^{3}(\mathrm{p}=0.035)$.

\section{Illustrative Case With a Complication}

Among the 200 patients, 1 patient experienced a severe GKS-related complication. The man, who was in his 70s and harbored a long-known lung adenocarcinoma, presented with ataxia. Magnetic resonance images showed an enhanced lesion at the pons. The tumor volume was $3.4 \mathrm{~cm}^{3}$. The tumor was covered with a $60 \%$ isodose gradient, and a central dose of 30.0 Gy was selected to obtain a peripheral dose of $18.0 \mathrm{~Gy}$ (Fig. 3A and B). With

TABLE 2: Univariate and multivariate analyses of prognostic factors for overall survival

\begin{tabular}{lrrrrr}
\hline & \multicolumn{2}{c}{ Univariate Analysis } & & \multicolumn{2}{c}{ Multivariate Analysis } \\
\cline { 2 - 3 } \cline { 5 - 6 } Variables & $\mathrm{p}$ Value & $\mathrm{HR}(95 \% \mathrm{Cl})$ & & $\mathrm{p} \mathrm{Value}$ & $\mathrm{HR}(95 \% \mathrm{Cl}))$ \\
\hline patient age & 0.072 & & & \\
patient sex & 0.439 & & & \\
KPS & $<0.001$ & $4.966(2.666-9.134)$ & & $<.001$ & $5.416(2.507-11.479)$ \\
tumor number & 0.005 & $2.097(1.251-3.473)$ & & 0.012 & $2.065(1.174-3.598)$ \\
tumor volume & 0.041 & $2.199(1.035-4.288)$ & & 0.856 & $1.099(0.382-2.956)$ \\
peripheral dose & 0.542 & & & \\
primary tumor status & $<0.001$ & $1.762(1.278-2.465)$ & & 0.021 & $1.494(1.061-2.128)$ \\
extracranial metastases & 0.222 & & & \\
neurological symptoms & 0.296 & & & \\
prior WBRT & 0.572 & & & & \\
\hline
\end{tabular}



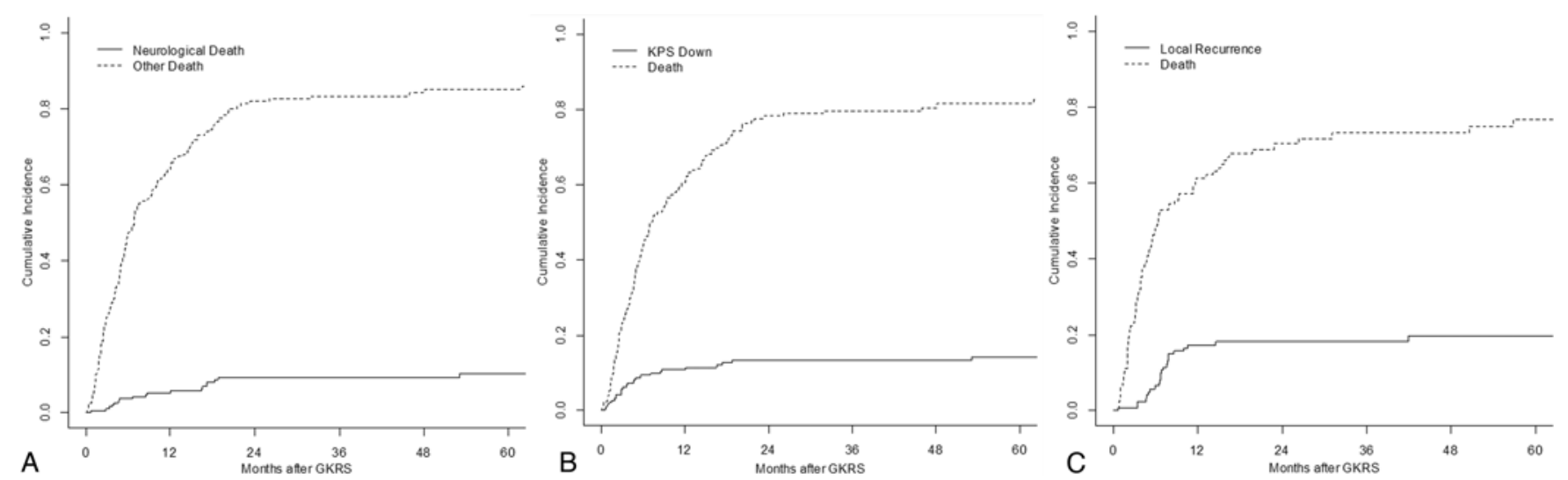

FIG. 2. Neurological death (A), qualitative deterioration (B), and local recurrence (C) estimated using competing risk analysis.

this dose planning, the conformity and gradient indexes were estimated to be 0.86 and 2.87 , respectively. ${ }^{21}$ The patient's condition gradually worsened for 9 months after treatment, and MR imaging demonstrated severe edema (Fig. 3C-E). Although steroid therapy was administered for several months, the man's condition continued to deteriorate. He eventually died of this treatment-related complication 16 months after GKS.

An additional 6 patients were administered oral steroids for 1-3 months after SRS because MR imaging demonstrated an increase in peritumoral edema. However, all 6 patients remained asymptomatic.

\section{Discussion}

To date, 14 series (a linear accelerator system was used in 5 series and a Gamma Knife in 9 series) have demonstrated the clinical efficacy of SRS for the treatment of brainstem metastases (Table 3), $4,7,8,10,13-16,18,22,25,28,33,34$ To the best of our knowledge, this is the first report based on a relatively large number of patients to describe GKS for brainstem metastases in which the focus was on neurological and qualitative survivals. These issues are crucial and should be given consideration in the management of patients with brain metastasis.

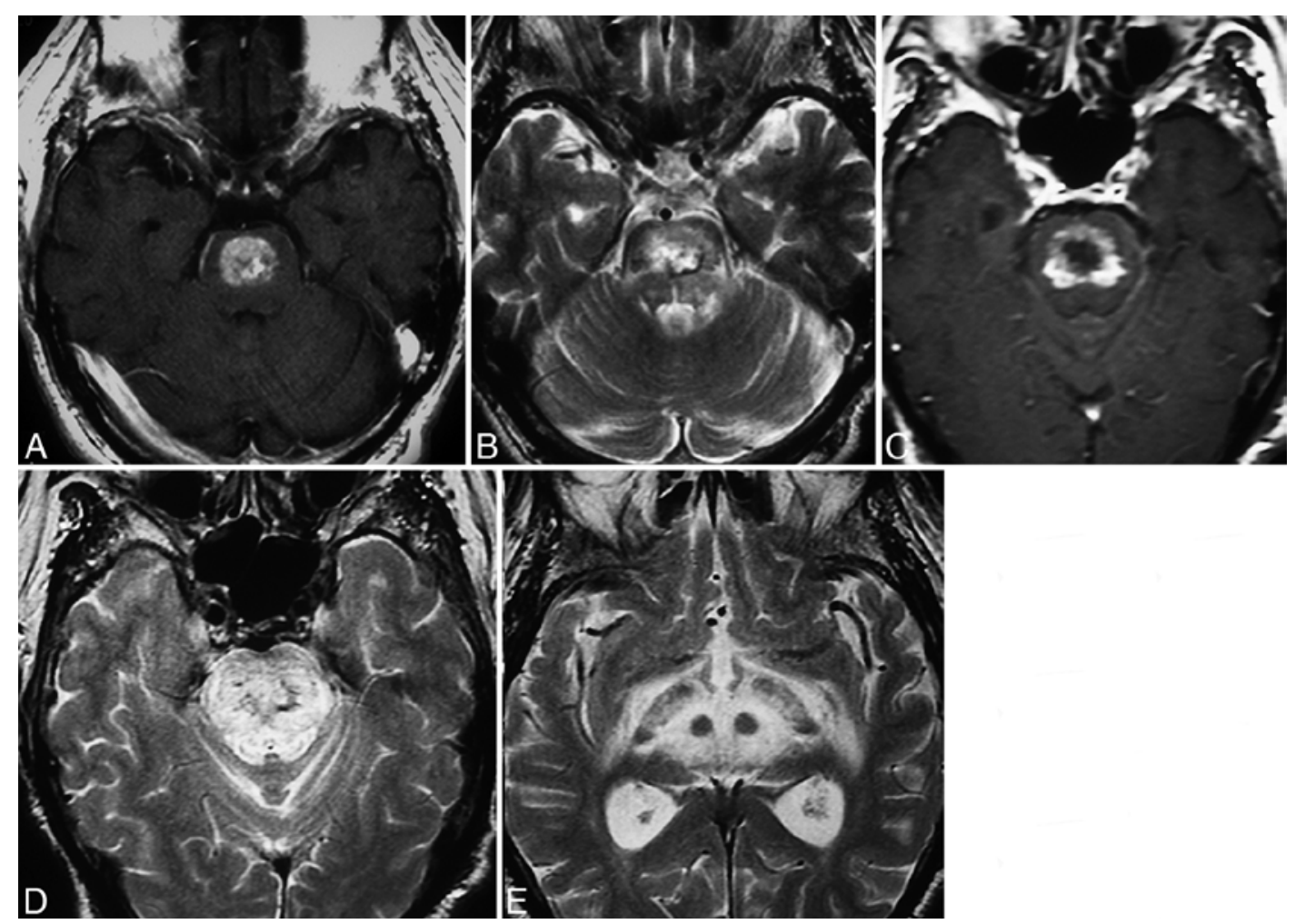

FIG. 3. Gadolinium-enhanced T1-weighted MR images obtained before (A) and 9 months after (C) GKS, and T2-weighted MR images obtained before (B) and 9 months after (D and E) GKS in a patient with a severe GKS-induced complication (see text for further description). 
TABLE 3: Summary of published reports of SRS for brainstem metastases*

\begin{tabular}{|c|c|c|c|c|c|c|}
\hline Authors \& Year & Treatment Modality & $\begin{array}{c}\text { No. of } \\
\text { Patients }\end{array}$ & $\begin{array}{c}\text { Tumor Vol } \\
\left(\mathrm{cm}^{3}\right) \dagger\end{array}$ & $\begin{array}{l}\text { Prescribed } \\
\text { Dose (Gy) } \ddagger\end{array}$ & MST (mos) & Local Control (\%) \\
\hline Huang et al., 1999 & GKS & 26 & 1.1 & 16 & 9 & 95 \\
\hline Shuto et al., 2003 & GKS & 25 & 2.1 & 13 & 4.9 & 77 \\
\hline Fuentes et al., 2006 & GKS & 28 & 2.1 & 19.6 & 12 & 92 \\
\hline Yen et al., 2006 & GKS & 53 & 2.8 & 17.6 & 11 & 87 \\
\hline Hussain et al., 2007 & GKS & 22 & 0.9 & 16 & 8.5 & 100 \\
\hline Kased et al., 2008 & GKS & 42 & 0.26 & 16 & 9 & 85 \\
\hline Lorenzoni et al., 2009 & GKS & 25 & 0.6 & 20 & 11.1 & 95 \\
\hline Samblás et al., 2009 & LINAC & 28 & 1.86 & 11 & 16.8 & NA \\
\hline Koyfman et al., 2010 & GKS & 43 & 0.37 & 15 & 5.8 & 85 \\
\hline Kelly et al., 2011 & LINAC & 24 & 0.2 & 13 & 5.3 & 79 \\
\hline Hatiboglu et al., 2011 & LINAC & 60 & 1.0 & 15 & 4 & 76 \\
\hline Valery et al., 2011 & LINAC & 30 & 2.8 & 13.4 & 10 & 79 \\
\hline Yoo et al., 2011 & GKS & 32 & 1.5 & 15.9 & 7.7 & 88 \\
\hline Lin et al., 2012 & LINAC & 48 & 0.4 & 14 & 11.6 & 91 \\
\hline present study & GKS & 200 & 1.3 & 18 & 6.0 & 82 \\
\hline
\end{tabular}

\section{Overall Survival}

Among previous reports, overall MSTs varied from 4.0 to 16.8 months. Although brainstem metastases have generally been regarded as a poor prognostic factor, some authors reported MSTs of more than 12 months-longer than those usually expected in patients with brain metastases., ${ }^{4,22}$ Recent advances in cancer treatment, as well as in SRS, which allow radical treatment of brain metastases, may have contributed greatly to prolonged overall survival. Nowadays, approximately $90 \%$ of patients with brain metastasis die as a result of progression of the systemic disease. Thus, these MST differences among reported series may reflect a bias in patient selection.

An improved prognostic index may resolve some of the uncertainty in making treatment decisions, specifically whether SRS should be performed. To date, 4 grading indexes have been proposed: 1) the Radiation Therapy Oncology Group's RPA $;{ }^{5}$ 2) the Score Index for Radiosurgery (SIR);29 3) the Basic Score for Brain Metastases (BSBM); $;{ }^{17}$ and 4) the Graded Prognostic Assessment (GPA). ${ }^{26}$ Table 4 shows MSTs in 3 or 4 subgroups according to the 4 systems as well as our subclassification of RPA Class II patients into 3 subclasses. ${ }^{32}$ Kaplan-Meier plots of our patient series showed statistically significant survival differences among patients stratified into 3 or 4 groups based on the 4 systems $(p<0.001)$. However, the MST differences between some pairs of groups failed to reach statistical significance with the 3 traditional systems-RPA, BSBM, and GPA-as well as with our subgroups of RPA Class II.

\section{Neurological and Qualitative Survivals}

Patients with metastases generally have poor prognoses. Therefore, it is important to prolong neurological and qualitative survival. There are several reports detailing causes of death. ${ }^{4,22,33,34}$ The rates of death caused by brain tumor progression range from $14 \%$ to $50 \%$, and the rates of death from brainstem tumor progression range from $4 \%$ to $13 \%$. In our series, the rate of death caused by brain tumor progression was $10.9 \%$ (19/175 patients), and the rate of brainstem tumor progression was 2.3\% (4/175 patients) - rates somewhat lower than those in previous reports. There were no statistically significant prognostic factors favoring neurological survival, but smaller tumors tended to be associated with prolonged neurological survival. In fact, as described herein, the rate of death caused by brainstem tumor progression was relatively low. However, we consider occasional assessments using MR imaging to detect small, asymptomatic brainstem lesions to be crucial for maintaining a better neurological state.

There are no previous reports on brainstem metastases in which patients' quality of life was assessed. Based on their large series of patients with brain metastasis, Serizawa et al. ${ }^{24}$ reported that pretreatment KPS score and carcinomatous meningitis were significant factors influencing qualitative survival. In the present study of brainstem metastases, we excluded cases with carcinomatous meningitis, but our results were similar to those of Serizawa et al. in terms of prognostic factors influencing qualitative survival.

\section{Local Control}

In previous reports, local control rates varied from $76 \%$ to $100 \% \%^{4,7,8,10,13,16,18,25,28,33}$ The differences among these rates were considered to reflect uncertainty in the definition of local control.

Several authors have described factors favoring local tumor control, such as tumor volume, peripheral dose, 
Gamma Knife surgery for brainstem metastases

TABLE 4: Overall median survival times in patients classified according to 4 indexes*

\begin{tabular}{|c|c|c|c|}
\hline Grade/Class & No. of Patients & MST in Mos $(95 \% \mathrm{Cl})$ & HR $(95 \% \mathrm{Cl}), \mathrm{p}$ Value \\
\hline \multicolumn{4}{|l|}{ RPA class } \\
\hline I & 20 & $9.4(5.5-16.6)$ & \\
\hline$\|$ & 171 & $5.9(4.9-7.0)$ & $1.41(0.88-2.42), p=0.159$, vs RPA I \\
\hline$\|-a$ & 29 & $10.2(5.5-18.3)$ & \\
\hline II-b & 53 & $9.1(5.6-14.5)$ & $1.51(0.92-2.56), p=0.104$, vs RPA II-a \\
\hline$\|-c$ & 89 & $4.7(3.5-5.8)$ & $1.78(1.24-2.58), p=0.002$, vs RPA II-b \\
\hline III & 9 & $1.9(0.4-6.9)$ & $2.94(1.39-5.48), p=0.007$, vs RPA II \\
\hline \multicolumn{4}{|l|}{ SIR } \\
\hline 8-10 & 25 & $16.5(8.8-26.1)$ & \\
\hline $4-7$ & 135 & $6.0(4.9-7.1)$ & $2.84(1.72-5.02), p<0.001$, vs SIR 8-10 \\
\hline $1-3$ & 40 & $3.3(2.1-5.2)$ & $1.67(1.14-2.38), p=0.009$, vs SIR 4-7 \\
\hline \multicolumn{4}{|l|}{ BSBM } \\
\hline 3 & 35 & $10.6(6.9-16.5)$ & \\
\hline 2 & 72 & $6.9(4.9-11.1)$ & $1.40(0.91-2.19), p=0.129$, vs BSBM 3 \\
\hline 1 & 76 & $5.0(3.8-6.0)$ & $1.49(1.06-2.11), p=0.023$, vs BSBM 2 \\
\hline 0 & 17 & $2.3(1.4-6.5)$ & $1.40(0.91-2.19), p=0.129$, vs BSBM 1 \\
\hline \multicolumn{4}{|l|}{ GPA } \\
\hline $3.5-4.0$ & 10 & $10.4(4.0-18.8)$ & \\
\hline 3.0 & 25 & $10.1(5.6-17.7)$ & $1.12(0.52-2.70), p=0.775$, vs GPA 3.5-4.0 \\
\hline $1.5-2.5$ & 116 & $5.9(4.7-7.1)$ & $1.64(1.04-2.68), p=0.030$, vs GPA 3.0 \\
\hline $0-1.0$ & 49 & $4.7(2.7-6.5)$ & $1.19(0.84-1.69), p=0.321$, vs GPA $1.5-2.5$ \\
\hline
\end{tabular}

* See Discussion for references to indexes.

melanoma as the primary cancer, and so on. In Japan, a primary melanoma is very rare, and there has been only 1 case of brainstem metastases from a melanoma. A smaller tumor volume, such as between 1.0 and $3.0 \mathrm{~cm}^{3}$, was shown to favor local tumor control. Also, we found that a peripheral dose $>18.0$ Gy contributed significantly to local tumor control.

A possible weakness in the present study is that neuroimaging follow-up was lacking in approximately $30 \%$ of patients. However, in most patients in this subset, MR imaging could not be performed due to early post-SRS death or remarkable deterioration in patients' general condition and not because the patients were lost to follow-up.

\section{Complications}

One of our patients experienced a fatal radiation-induced side effect. In this case, a peripheral dose of 18.0 Gy was delivered to a relatively large brainstem metastasis. Paddick and Lippitz ${ }^{21}$ reported that the gradient index may be a useful predictor of adverse effects. As described earlier in this paper, neither the conformity nor the gradient index was considered to have exceeded the safety range in this case. We compared the other 11 cases with brainstem metastases with tumor volumes $>3.0 \mathrm{~cm}^{3}$, in which follow-up MR images were available. The mean peripheral and central doses were 16.8 and 30.0 Gy, respectively, and the mean Paddick conformity and gradient indexes were 0.80 and 3.50 , respectively. The patient in this case received a slightly higher peripheral dose than the control group (18 vs $16.8 \mathrm{~Gy}$ ), but dose planning in regard to the conformity and gradient indexes was actually better. Since this experience, we have been especially cautious not only about conformity but also about the optimal dose for brainstem metastases.

Our database included 6 asymptomatic patients in whom steroid treatment was required to prevent peritumoral edema progression. However, the primary physicians who managed our GKS cases may not have reported rather minor problems to us. Therefore, an additional weakness of this study is that all patients with minor complications were not surveyed.

\section{Conclusions}

Our present results indicate that GKS is an effective treatment for brainstem metastases. A better KPS score, a single metastasis, and a well-controlled primary tumor were significant predictive factors favoring survival.

\section{Disclosure}

The authors report no conflict of interest concerning the materials or methods used in this study or the findings specified in this paper.

Author contributions to the study and manuscript preparation include the following. Conception and design: Kawabe, Yamamoto. Acquisition of data: Kawabe, Yamamoto. Analysis and interpretation of data: Kawabe. Drafting the article: Kawabe. Critically revising the article: all authors. Reviewed submitted version of manuscript: all authors. Approved the final version of the manuscript on behalf of all authors: Kawabe. Statistical analysis: Sato. Administrative/technical/material support: Urakawa, Kasuya. Study supervision: Yamamoto. 


\section{References}

1. Aoyama H, Shirato H, Tago M, Nakagawa K, Toyoda T, Hatano K, et al: Stereotactic radiosurgery plus whole-brain radiation therapy vs stereotactic radiosurgery alone for treatment of brain metastases: a randomized controlled trial. JAMA 295:2483-2491, 2006

2. Chang EL, Wefel JS, Hess KR, Allen PK, Lang FF, Kornguth DG, et al: Neurocognition in patients with brain metastases treated with radiosurgery or radiosurgery plus whole-brain irradiation: a randomised controlled trial. Lancet Oncol 10: 1037-1044, 2009

3. DeAngelis LM, Delattre JY, Posner JB: Radiation-induced dementia in patients cured of brain metastases. Neurology 39: 789-796, 1989

4. Fuentes S, Delsanti C, Metellus P, Peragut JC, Grisoli F, Regis $\mathrm{J}$ : Brainstem metastases: management using gamma knife radiosurgery. Neurosurgery 58:37-42, 2006

5. Gaspar L, Scott C, Rotman M, Asbell S, Phillips T, Wasserman T, et al: Recursive partitioning analysis (RPA) of prognostic factors in three Radiation Therapy Oncology Group (RTOG) brain metastases trials. Int J Radiat Oncol Biol Phys 37:745-751, 1997

6. Gooley TA, Leisenring W, Crowley J, Storer BE: Estimation of failure probabilities in the presence of competing risks: new representations of old estimators. Stat Med 18:695-706, 1999

7. Hatiboglu MA, Chang EL, Suki D, Sawaya R, Wildrick DM, Weinberg JS: Outcomes and prognostic factors for patients with brainstem metastases undergoing stereotactic radiosurgery. Neurosurgery 69:796-806, 2011

8. Huang CF, Kondziolka D, Flickinger JC, Lunsford LD: Stereotactic radiosurgery for brainstem metastases. J Neurosurg 91:563-568, 1999

9. Hunter KM, Rewcastle NB: Metastatic neoplasms of the brain stem. Can Med Assoc J 98:1-7, 1968

10. Hussain A, Brown PD, Stafford SL, Pollock BE: Stereotactic radiosurgery for brainstem metastases: Survival, tumor control, and patient outcomes. Int J Radiat Oncol Biol Phys 67:521524, 2007

11. Kano H, Kondziolka D, Lobato-Polo J, Zorro O, Flickinger JC, Lunsford LD: T1/T2 matching to differentiate tumor growth from radiation effects after stereotactic radiosurgery. Neurosurgery 66:486-492, 2010

12. Karnofsky DA, Burchenal JH: The clinical evaluation of chemotherapeutic agents in cancer, in MacLeod CM (ed): Evaluation of Chemotherapeutic Agents. New York: Columbia University Press, 1949, pp 191-205

13. Kased N, Huang K, Nakamura JL, Sahgal A, Larson DA, McDermott MW, et al: Gamma knife radiosurgery for brainstem metastases: the UCSF experience. J Neurooncol 86:195-205, 2008

14. Kelly PJ, Lin YB, Yu AY, Ropper AE, Nguyen PL, Marcus KJ, et al: Linear accelerator-based stereotactic radiosurgery for brainstem metastases: the Dana-Farber/Brigham and Women's Cancer Center experience. J Neurooncol 104:553-557, 2011

15. Koyfman SA, Tendulkar RD, Chao ST, Vogelbaum MA, Barnett GH, Angelov L, et al: Stereotactic radiosurgery for single brainstem metastases: the Cleveland clinic experience. Int J Radiat Oncol Biol Phys 78:409-414, 2010

16. Lin CS, Selch MT, Lee SP, Wu JK, Xiao F, Hong DS, et al: Accelerator-based stereotactic radiosurgery for brainstem metastases. Neurosurgery 70:953-958, 2012

17. Lorenzoni J, Devriendt D, Massager N, David P, Ruíz S, Vanderlinden B, et al: Radiosurgery for treatment of brain metastases: estimation of patient eligibility using three stratification systems. Int J Radiat Oncol Biol Phys 60:218-224, 2004

18. Lorenzoni JG, Devriendt D, Massager N, Desmedt F, Simon S, Van Houtte P, et al: Brain stem metastases treated with radiosurgery: prognostic factors of survival and life expectancy estimation. Surg Neurol 71:188-196, 2009
19. Mathieu D, Kondziolka D, Flickinger JC, Fortin D, Kenny B, Michaud K, et al: Tumor bed radiosurgery after resection of cerebral metastases. Neurosurgery 62:817-824, 2008

20. Nariai T, Tanaka Y, Wakimoto H, Aoyagi M, Tamaki M, Ishiwata $\mathrm{K}$, et al: Usefulness of L-[methyl-11C] methioninepositron emission tomography as a biological monitoring tool in the treatment of glioma. J Neurosurg 103:498-507, 2005

21. Paddick I, Lippitz B: A simple dose gradient measurement tool to complement the conformity index. J Neurosurg $\mathbf{1 0 5}$ Suppl:194-201,2006

22. Samblás JM, Sallabanda K, Bustos JC, Gutiérrez-Díaz JA, Peraza C, Beltrán C, et al: Radiosurgery and whole brain therapy in the treatment of brainstem metastases. Clin Transl Oncol 11:677-680, 2009

23. Satagopan JM, Ben-Porat L, Berwick M, Robson M, Kutler $\mathrm{D}$, Auerbach AD: A note on competing risks in survival data analysis. Br J Cancer 91:1229-1235, 2004

24. Serizawa T, Saeki N, Higuchi Y, Ono J, Iuchi T, Nagano O, et al: Gamma knife surgery for brain metastases: indications for and limitations of a local treatment protocol. Acta Neurochir (Wien) 147:721-726, 2005

25. Shuto T, Fujino H, Asada H, Inomori S, Nagano H: Gamma knife radiosurgery for metastatic tumours in the brain stem. Acta Neurochir (Wien) 145:755-760, 2003

26. Sperduto PW, Berkey B, Gaspar LE, Mehta M, Curran W: A new prognostic index and comparison to three other indices for patients with brain metastases: an analysis of 1,960 patients in the RTOG database. Int J Radiat Oncol Biol Phys 70:510-514, 2008

27. Tsuyuguchi N, Sunada I, Iwai Y, Yamanaka K, Tanaka K, Takami T, et al: Methionine positron emission tomography of recurrent metastatic brain tumor and radiation necrosis after stereotactic radiosurgery: is a differential diagnosis possible? J Neurosurg 98:1056-1064, 2003

28. Valery CA, Boskos C, Boisserie G, Lamproglou I, Cornu P, Mazeron JJ, et al: Minimized doses for linear accelerator radiosurgery of brainstem metastasis. Int J Radiat Oncol Biol Phys 80:362-368, 2011

29. Weltman E, Salvajoli JV, Brandt RA, de Morais Hanriot R, Prisco FE, Cruz JC, et al: Radiosurgery for brain metastases: a score index for predicting prognosis. Int J Radiat Oncol Biol Phys 46:1155-1161, 2000

30. Yamamoto M: Radiosurgery for metastatic brain tumors. Prog Neurol Surg 20:106-128, 2007

31. Yamamoto M, Ide M, Nishio S, Urakawa Y: Gamma Knife radiosurgery for numerous brain metastases: is this a safe treatment? Int J Radiat Oncol Biol Phys 53:1279-1283, 2002

32. Yamamoto M, Sato Y, Serizawa T, Kawabe T, Higuchi Y, Nagano O, et al: Subclassification of recursive partitioning analysis Class II patients with brain metastases treated radiosurgically. Int J Radiat Oncol Biol Phys 83:1399-1405, 2012

33. Yen CP, Sheehan J, Patterson G, Steiner L: Gamma knife surgery for metastatic brainstem tumors. J Neurosurg 105:213219, 2006

34. Yoo TW, Park ES, Kwon H, Kim CJ: Gamma knife radiosurgery for brainstem metastasis. J Korean Neurosurg Soc 50: 299-303, 2011

Manuscript submitted May 14, 2012.

Accepted July 10, 2012.

This work was presented at the 16th International Meeting of the Leksell Gamma Knife Society, March 25-29, 2012, in Sydney, Australia.

Please include this information when citing this paper: DOI: 10.3171/2012.7.GKS12977.

Address correspondence to: Takuya Kawabe, M.D., Katsuta Hospital Mito GammaHouse, 5125-2 Nakane, Hitachi-naka, Ibaraki 312-0011, Japan. email: taku-62@koto.kpu-m.ac.jp. 